\title{
Gender Differences in the Clinical and Polysomnographic Characteristics Among Australian Aboriginal Patients with Obstructive Sleep Apnea
}

This article was published in the following Dove Press journal:

Nature and Science of Sleep

\author{
Sumit Mehra $\mathbb{D}^{1,2}$ \\ Ram H Ghimire' \\ Joy J Mingi, ${ }^{3,4}$ \\ Monica Hatch' \\ Himanshu Garg' \\ Robert Adams ${ }^{5}$ \\ Subash S Heraganahally $\mathbb{D}^{1,3}$ \\ 'Department of Respiratory and Sleep \\ Medicine, Royal Darwin Hospital, \\ Darwin, Northern Territory, Australia; \\ ${ }^{2}$ Department of Respiratory and Sleep \\ Medicine, Flinders Medical Centre, \\ Adelaide, South Australia, Australia; \\ ${ }^{3}$ Darwin Respiratory and Sleep Health, \\ Darwin Private Hospital, Darwin, \\ Northern Territory, Australia; \\ ${ }^{4}$ Department of Public Health, Charles \\ Darwin University, Darwin, Northern \\ Territory, Australia; ${ }^{5}$ Adelaide Institute \\ for Sleep Health, a Flinders Centre for \\ Research Excellence, Bedford Park, South \\ Australia, Australia
}

Correspondence: Subash S Heraganahally Email hssubhashcmc@hotmail.com
Background: In this study, we assessed the clinical and polysomnographic (PSG) characteristics according to gender among Australian Aboriginal men and woman diagnosed to have obstructive sleep apnea (OSA).

Methods: In this retrospective study, all adult Aboriginal patients over 18 years of age diagnosed to have OSA with an apnea hypopnea index $(\mathrm{AHI})>5$ /hour over a 5 year period were included.

Results: Of the 337 patients (168 females and 169 males), who underwent a diagnostic PSG, 297 (88\%) were diagnosed to have OSA (AHI) >5/hour), 154/297 males (52\%) and 143/297 females (48\%). Amongst male and female patients with OSA, $63 \%$ and $37 \%$ were in the severe spectrum (AHI $>30 /$ hour). The male cohort had higher stage N1 NREM sleep $(P<0.001)$, reduced N3 NREM sleep $(P<0.001)$, higher AHI severity $(P<0.001)$, higher NREM AHI $(P<0.001)$, and high arousal index $(P<0.005)$. REM sleep-related AHI was higher among female patients with all severity of OSA, along with severe oxygen desaturation during REM sleep. Among patients with severe OSA, the female cohort were younger (age 46 years vs 49 years, $P=0.030$ ) and had higher BMI with all severity of OSA, while males had larger neck circumference compared to females. Hypertension increased the odds of severe OSA versus the combined odds of mild and moderate OSA for both genders.

Conclusion: This study highlights some important differences in the way sleep apnea manifests in Australian Aboriginal males and females and further studies are warranted to explore avenues to look for a physiological basis for these observations and targeted interventions.

Keywords: aboriginal, ethnic, female, gender, male, obstructive sleep apnea

\section{Summary}

Obstructive Sleep Apnea (OSA) is increasingly being recognized among females, and emerging evidence suggests that there are significantly different gender aspects of OSA. However, the literature in regards to the sex differences in the clinical manifestation and sleep study parameters on OSA is scant. In this retrospective study, we evaluated and compared the demographic, clinical, and sleep study details of adult Australian Aboriginal male and female patients diagnosed to have OSA. This is probably the first study comparing the sleep health profile of this male and female Indigenous/Aboriginal population. Our study showed that severe sleep apnea was associated more commonly with male gender, with females having predominant REM sleep related OSA. Females with severe OSA were younger, 
and had higher BMI, in contrast to males who had larger neck circumference. Males with OSA have more fragmented and poor sleep quality. The presence of high blood pressure increases the odds of having severe OSA versus the combined odds of mild and moderate OSA for both genders. The results of our study highlight the clinical and gender differences in an Aboriginal population and may be helpful for further research to implement management strategies of OSA in this population.

\section{Introduction}

Obstructive sleep apnea (OSA) is a global health issue with a prevalence estimated in the general adult population to be between $6-17 \%{ }^{1-3}$ More recently, OSA is being increasingly recognised as a heterogeneous disorder with varying clinical phenotypic representations. ${ }^{4-7}$ Moreover, individual's ethnicity and gender is considered to represent one of the important phenotype variants in the clinical manifestations of patients with OSA. ${ }^{8,9}$ Furthermore, OSA has been assumed to be a male predominant disease and most of our knowledge on OSA comes largely from male population-based studies. However, it is being increasingly recognised among women and the male-tofemale ratio is estimated to be between $2: 1$ and $3: 1 .^{10-12}$ The differences in prevalence, though not fully understood, however, are thought to be related to variation in craniofacial morphology, pattern of fat deposition, effect of sex hormones, and menopause. ${ }^{13-17}$ Under-recognition of OSA in women in clinical settings may occur due to sociocultural and ethnic factors combined with varied clinical expression.

Published studies on ethnic and gender differences in the clinical manifestation of OSA has mostly come from populations involving Caucasians, African Americans, and Hispanics. ${ }^{8,9,18-20}$ However, worldwide approximately 370 million people are estimated to be of Indigenous descent and live in over 90 countries and are thought to make up for about $5 \%$ of the global population. ${ }^{21,22}$ In Australia, 3.3\% of the population are considered to be of Aboriginal and Torres Strait Islander (ATSI) origin. However, in the Northern Territory (NT) of Australia about $30 \%$ of the population are Australian Aboriginals, the highest proportion among all Australian States and Territories and follow traditional Indigenous culture and belief. ${ }^{23}$ Furthermore, OSA is also being increasingly recognized in the Indigenous/Aboriginal population and studies have demonstrated that Indigenous/Aboriginal patients have a higher chance of having OSA compared to non- Indigenous/Aboriginals. ${ }^{24-27} \mathrm{~A}$ recent study from our center had demonstrated that a higher proportion of ATSI patients were noted to have severe OSA. ${ }^{28}$

Although there is growing evidence to suggest that OSA manifests differently in different ethnic populations and has gender differences; however, there is limited evidence in the literature with regards to the ethnic and gender influence among Australian or other Indigenous/Aboriginal populations. Hence, it would be more meaningful to study a homogenous NT Australian Aboriginal cohort with a similar genetic/ethnic pool exposed to similar environmental and cultural conditions. Therefore, the aim of this study was to assess gender differences in clinical and polysomnographic (PSG) characteristics in Australian Aboriginal patients with OSA patients at the NT, Top End Health Service region (TEHS) of Australia.

\section{Methods}

\section{Study Participants}

The study participants who self-identified as only of Australian Aboriginals aged 18 years and over from our previous study cohort $^{28}$ were included in this study. Patients who identified to be of both Aboriginal and/or Torres Strait Islander origin (ATSI) or Torres Strait Islander origin alone (TSI) were excluded from the study, in order for this study to represent a uniquely defined Australian Aboriginal cohort with similar genetic/ethnic, cultural pool, exposed to similar environmental and living conditions. Where information on gender or aboriginality was not clear from the data set the patients were excluded from the analysis.

The patients were referred to the specialist sleep service based at the Royal Darwin Hospital (RDH) and Darwin Private Hospital (DPH), Darwin, by primary health practitioners and other specialist physicians for assessment of clinically suspected sleep disorders, in particular OSA. Patients underwent a diagnostic PSG as per the discretion of the treating respiratory and sleep physician following an initial clinical consultation.

\section{Clinical Data}

As per standard protocol at our sleep diagnostic facility, all patients were administered with a detailed questionnaire by the sleep technologist prior to undergoing a diagnostic PSG. For non-English speaking patients, language interpreters or family members assisted with the questionnaire 
when available. The questionnaire was designed to provide information on demographics, Aboriginal status, age, sex, alcohol consumption, smoking history, and medical comorbid conditions, such as the presence of diabetes, hypertension, and heart disease (including cardiac arrhythmia, coronary artery disease, and rheumatic heart disease). To assess subjective daytime symptoms of sleep disorder, the Epworth Sleepiness Scale (ESS) was utilized. Anthropometric measurements including weight, height, neck circumference (in the standing position at the level of the cricothyroid membrane), and body mass index (BMI) were also recorded.

\section{Polysomnography (PSG)}

Level 1 and level 2 PSGs were performed at the Darwinbased sleep service facility accredited by the National Association of Testing Authorities, Australia (NATA) and the Australian Sleep Association (ASA). The sleep studies which were performed and analysed during this study period were according to the 2007 American Academy of Sleep Medicine recommendations and as described in the previous study. ${ }^{28}$ All failed sleep studies, type 3, type 4 (limited sleep studies), continuous positive airway pressure (CPAP) initiation/titration studies, and studies in which AHI or sleep architecture was not available were excluded.

\section{Statistical Considerations}

Statistical analysis was conducted in Stata/SE 15. The assumption of normality was checked using ShapiroWilk test. The data are not normally distributed. Thus, continuous data was described with median and interquartile range (IQR) and was analyzed with a Wilcoxon ranksum (Mann-Whitney) test. Categorical data was described with count and percentages and was analysed with a chisquared $\left(\chi^{2}\right)$ test.

The participants' characteristics were first compared according to gender and second according to gender in each OSA category. Ordered logistic regression was used to investigate what factors influence the severity of OSA in male and female genders. These factors include participants' demographic characteristics and medical co-morbid conditions. Statistical significance is set at $P<0.05$. All individual clinical parameters were analyzed as per medical records entries. The numbers of available information of each individual data are shown in respective areas when appropriate.

\section{Ethical Consideration}

This study is a part of the NT sleep health study approved by the Human Research Ethics Committee of the Northern Territory Health Service (TEHS) and Menzies School of Health Research. (Reference no: HREC2012-1886). Individual consent from the study participants was not obtained, as the study was retrospective in nature and no active pharmacological or non-pharmacological interventions were investigated during this study. Investigators involved in this study are the usual specialist care providers for the patients included in this study and have access to patients' medical records and sleep study reports as a part of their usual medical care. Hence, separate patients' consent to access their medical records or the sleep study reports was not required.

\section{Results \\ Demographic and Baseline Clinical Characteristics}

There were a total of 337 patients who were identified as Aboriginal Australians only and had undergone a diagnostic PSG during the study period (2011-2015). There were similar numbers of women $(168,49.9 \%)$ to men $(169,50.1 \%)$ within this group. Out of these 337 who had a diagnostic PSG, 297 (88\%) patients were noted to have OSA (AHI $>5$ / h), 154/297 males (51.8\%) and 143/297 females (48.2\%). The study results/analysis are representative of the 297 of the study cohort diagnosed to have OSA. Table 1 shows the demographic characteristics, Epworth Sleepiness score (ESS), smoking, alcohol history, and medical co-morbid conditions among both male and female study participants. Women had higher BMI compared to men $(P=0.006)$, whilst men had larger neck circumferences compared to women $(P<0.001)$ and ESS scores were similar among both men and women. Medical co-morbid conditions were noted to be highly prevalent, equally noted in both men and women, with diabetes (138, 46.5\%), hypertension (131, 44.1\%), and cardiovascular disease $(116,39.1 \%)$.

\section{Polysomnography Data}

Polysomnography findings comparing male and female patients are shown in Table 2. Women with OSA had more slow wave or stage N3 non-rapid eye movement (NREM) sleep $(P<0.001)$ and higher spontaneous arousal index $(P=0.021)$ compared to men. Percentage of stage N1 non rapid eye movement sleep $(P<0.001)$, respiratory arousal index $(P<0.001)$, total arousal index $(P=0.005)$, 
Table I Comparison of Demographic Characteristics and Medical Co-Morbid Conditions Among Both Male and Female Study Participants with Obstructive Sleep Apnea

\begin{tabular}{|l|l|l|l|l|}
\hline Variables & Female & Male & All Patients & P-value \\
\hline Sex & $143(48.2 \%)$ & $154(51.8 \%)$ & $297(100 \%)$ \\
Age (years) & $48.7(39.4-55.8)$ & $47(39.7-57.7)$ & $47.8(39.7-56.5)$ & $100(86-116.8)$ \\
*Weight (kg) & $94(83-115.5)$ & $103.2(89.4-118)$ & $35.2(30.6-40.7)$ & 0.976 \\
*BMI & $35.8(32.1-43.2)$ & $34.6(30.1-39.4)$ & $44(40-47.5)$ & $10(6-14)$ \\
*Neck circ (cm) & $38.5(35.0-41.0)$ & $46(43-49)$ & 150 & 0.011 \\
ESS & $11(7-16)$ & $10(6-14)$ & 122 & \\
Smoking & $73(51.0 \%)$ & $77(50.0 \%)$ & $138(46.5 \%)$ & $131(44.1 \%)$ \\
*Alcohol History & $47(32.9 \%)$ & $75(48.7 \%)$ & $116(39.1 \%)$ & 0.006 \\
Diabetes & $73(51.0 \%)$ & $65(42.2 \%)$ & $86(29.0 \%)$ & 0.161 \\
Hypertension & $62(43.4 \%)$ & $69(44.8 \%)$ & $68(22.9 \%)$ & 0.011 \\
Heart Disease & $53(37.1 \%)$ & $63(40.9 \%)$ & 0.802 \\
COPD & $46(32.2 \%)$ & $40(26.0 \%)$ & 0.497 \\
CKD & $33(23.1 \%)$ & $35(22.7 \%)$ & 0.943 \\
\hline
\end{tabular}

Notes: Data are presented as median (interquartile range) and $\mathrm{n}(\%)$. *Statistically significant.

Abbreviations: BMI, body mass index; AF, atrial fibrillation; CKD, chronic kidney disease; COPD, chronic obstructive pulmonary disease; ESS, Epworth sleepiness scale; Circ, circumference; $n$, numbers.

Table 2 Comparison of Polysomnographic Results Among Male and Female Study Participants with Obstructive Sleep Apnea

\begin{tabular}{|c|c|c|c|c|}
\hline PSG Variables & Female & Male & All Participants & P-value \\
\hline Total & 143 & 154 & 297 & \\
\hline Sleep Latency $(\mathrm{min})$ & $20(7.2-40.5)$ & $16.6(5.5-4 \mid .6)$ & $\mid 8.5(6.2-4 \mid .3)$ & 0.386 \\
\hline REM Onset (min) & $107(74-183.5)$ & $121(75-188)$ & II $5.8(74.5-187.25)$ & 0.676 \\
\hline Wake After Sleep Onset (min) & $74(45.1-116.2)$ & $91.4(44.5-173)$ & $81.25(44.8-148.05)$ & 0.123 \\
\hline Sleep Efficiency (\%) & $77.7(68.2-86.0)$ & $74.4(60.4-85.9)$ & $76.5(64.3-86.0)$ & 0.125 \\
\hline Total Sleep Time (min) & $388.5(338-451.5)$ & $379.5(296.5-437)$ & $385.0(319.8-439.0)$ & 0.181 \\
\hline *NI Sleep Percentage & $9.6(6.1-17.1)$ & I8.2(II.7 29.4) & I $3.4(8-23.7)$ & 0.001 \\
\hline N2 Sleep Percentage & $53.9(43.9-60.4)$ & $51.5(39.3-61.6)$ & $52.6(41.4-60.9)$ & 0.570 \\
\hline *N3 Sleep Percentage & II.9 (4.3-20.6) & $4.4(0.6-11.3)$ & $8.3(1.6-15.9)$ & 0.000 \\
\hline Stage REM Percentage & $17.7(10.9-22.3)$ & $17(11.2-22.9)$ & $17.3(11.2-22.3)$ & 0.799 \\
\hline *Respiratory Arousal Index (/h) & $9.9(4.0-18.9)$ & $18(6.9-38.7)$ & $12.5(5.6-27.1)$ & 0.000 \\
\hline Limb Related Arousal Index (/h) & $4.4(2.5-8.3)$ & $3.7(1.9-7.6)$ & $4.1(2.1-7.8)$ & 0.269 \\
\hline *Spontaneous Arousal Index (/h) & $3.4(1.7-6.3)$ & $2.4(0.9-5.3)$ & $3.1(1.2-5.8)$ & 0.021 \\
\hline *Total Arousal Index (/h) & $23.8(15.8-34.9)$ & $28.4(18.3-48)$ & $25.8(|6.8-4|)$ & 0.005 \\
\hline *Total AHI (/h) & $21.9(12.6-45.5)$ & $44.3(20.3-67.2)$ & $32(14.7-60.7)$ & 0.001 \\
\hline *NREM AHI (/h) & $17.2(7.4-43.6)$ & $46.4(18.5-67.9)$ & $27.2(10.8-60.6)$ & 0.001 \\
\hline REM AHI (/h) & $41.55(22.5-73.4)$ & $42.9(22.5-68.9)$ & $41.9(22.5-71.6)$ & 0.689 \\
\hline Avg $\mathrm{SpO}_{2}$ : Wake & $95(93-96)$ & $95(93-96)$ & $95(93-96)$ & 0.436 \\
\hline Avg $\mathrm{SpO}_{2}: \mathrm{NREM}$ & $93(91-95)$ & $93(91-95)$ & $93(91-95)$ & 0.346 \\
\hline Avg $\mathrm{SpO}_{2}: \mathrm{REM}$ & $93(89-95)$ & $93(88-95)$ & $93(89-95)$ & 0.928 \\
\hline Minimum $\mathrm{SpO}_{2}$ During Sleep (\%) & $80(70-85)$ & $76.5(65-85)$ & $78(68-85)$ & 0.133 \\
\hline
\end{tabular}

Notes: Data are presented as median (interquartile range). *Statistically significant.

Abbreviations: AHI, apnea hypopnea index; REM, rapid eye movement; NRE, non rapid eye movement; NI, N2, N3, non-rapid eye movement sleep stage; Avg SpO ${ }_{2}$, average oxygen saturation; /h, per hour.

total AHI $(P<0.001)$, and NREM AHI $(P<0.001)$ were significantly higher among males compared to females. The median total AHI among male OSA patients was 44.3 events/hour in comparison to 21.9 events/ hour amongst female patients.

\section{Clinical Characteristic According to} Apnea Hypopnea Index in Both Gender

The clinical and demographic characteristic for both male and female gender according to AHI severity, $\mathrm{AHI}<5$ (normal range), $\mathrm{AHI}=5-15$ (mild sleep apnea), 
AHI=15-30 (moderate sleep apnea), AHI $>30$ (severe sleep apnea) are shown in Table 3. Amongst those with OSA, severe OSA was present in more than half $(52.2 \%)$, more so among males, accounting for more than $60 \%$. Moreover, amongst male and female patients with OSA, $62.6 \%$ and $37.4 \%$ were in the severe spectrum, respectively. Among patients with severe OSA, the female cohort were younger and had higher BMI with all

Table 3 Demographic Characteristics and Medical Co-Morbid Conditions in Male and Female Study Participants According to Apnea Hypopnea Index

\begin{tabular}{|c|c|c|c|c|}
\hline \multicolumn{2}{|c|}{ Clinical Characteristics } & \multirow{2}{*}{$\begin{array}{l}\text { Mild (AHI 5-I 5) } \\
76(25.6 \%)\end{array}$} & \multirow{2}{*}{$\begin{array}{l}\text { Moderate (AHI I5-30) } \\
66(22.2 \%)\end{array}$} & \multirow{2}{*}{$\begin{array}{l}\text { Severe }(\mathbf{A H I}>\mathbf{3 0}) \\
155(52.2 \%)\end{array}$} \\
\hline Total & & & & \\
\hline \multirow[t]{2}{*}{ Sex } & Female & 51 (67.l\%) & $34(51.5 \%)$ & $58(37.4 \%)$ \\
\hline & Male & $25(32.9 \%)$ & 32 (48.5\%) & 97 (62.6\%) \\
\hline \multirow[t]{3}{*}{ Age (years) } & Female & $50.6(4 \mid .5-62.0)$ & $50.2(44.2-57.1)$ & $46.5(36-52.7)$ \\
\hline & Male & $45.7(36-54.5)$ & $45.9(39.6-54.3)$ & $48.9(39.8-58.4)$ \\
\hline & $P$-value & 0.124 & 0.243 & $* 0.030$ \\
\hline \multirow[t]{3}{*}{ Weight (kg) } & Female & $92(80.5-106.8)$ & $96(81.5-110)$ & $94.2(84-130)$ \\
\hline & Male & $100(84.8-110.2)$ & $96(88-110)$ & $106.3(91-120.9)$ \\
\hline & $P$-value & 0.365 & 0.606 & 0.226 \\
\hline \multirow[t]{3}{*}{ BMI } & Female & $35.1(30.5-41.0)$ & $35.8(32.4-40.4)$ & $40.3(32.2-46.4)$ \\
\hline & Male & $32.5(28.1-37.6)$ & $31.9(29.3-36.1)$ & $35.8(31-40.6)$ \\
\hline & $P$-value & 0.057 & $* 0.010$ & 0.063 \\
\hline \multirow[t]{3}{*}{ Neck Circ (cm) } & Female & $40(36.5-43)$ & $40(37-44)$ & $44(40.5-46.5)$ \\
\hline & Male & $44(42-46.5)$ & $45.3(42-48)$ & $47(44-50)$ \\
\hline & $P$-value & $* 0.001$ & $* 0.001$ & $* 0.001$ \\
\hline \multirow[t]{3}{*}{ ESS } & Female & $10(6-14)$ & $12(7-17)$ & $11(8-16)$ \\
\hline & Male & $7.5(5-11)$ & $9(6-12)$ & $10(6-15)$ \\
\hline & $P$-value & 0.1813 & 0.1573 & 0.5359 \\
\hline \multirow[t]{3}{*}{ Diabetes } & Female & $28(54.9 \%)$ & I8 (52.9\%) & 27 (46.6\%) \\
\hline & Male & II (44.0\%) & $15(46.9 \%)$ & 39 (40.2\%) \\
\hline & $P$-value & 0.372 & 0.622 & 0.439 \\
\hline \multirow[t]{3}{*}{ Hypertension } & Female & 19 (37.3\%) & 19 (55.9\%) & 24 (4I.4\%) \\
\hline & Male & $9(36.0 \%)$ & 12 (37.5\%) & 48 (49.5\%) \\
\hline & $P$-value & 0.915 & 0.135 & 0.328 \\
\hline \multirow[t]{3}{*}{ Heart Disease } & Female & 16 (31.4\%) & 14 (4I.2\%) & 23 (39.7\%) \\
\hline & Male & $10(40.0 \%)$ & 15 (46.9\%) & 38 (39.2\%) \\
\hline & $P$-value & 0.456 & 0.641 & 0.953 \\
\hline \multirow[t]{3}{*}{ COPD } & Female & $2 \mathrm{I}(4 \mathrm{I} .2 \%)$ & $13(38.2 \%)$ & 12 (20.7\%) \\
\hline & Male & $8(32.0 \%)$ & 8 (25.0\%) & 24 (24.7\%) \\
\hline & Pvalue & 0.439 & 0.249 & 0.563 \\
\hline \multirow[t]{3}{*}{ CKD } & Female & $13(25.5 \%)$ & 7 (20.6\%) & 13 (22.4\%) \\
\hline & Male & 2 (8.0\%) & II (34.4\%) & 22 (22.7\%) \\
\hline & $P$-value & 0.072 & 0.209 & 0.969 \\
\hline \multirow[t]{3}{*}{$A F$} & Female & $6(11.8 \%)$ & $3(8.8 \%)$ & $10(17.2 \%)$ \\
\hline & Male & $5(20.0 \%)$ & $3(9.4 \%)$ & 12 (12.4\%) \\
\hline & $P$-value & 0.338 & 0.938 & 0.400 \\
\hline
\end{tabular}

Notes: Data are presented as median (interquartile range) and $\mathrm{n}(\%)$. *Statistically significant.

Abbreviations: AHI, apnea hypopnea index; BMI, body mass index; AF, atrial fibrillation; CKD, chronic kidney disease; COPD, chronic obstructive pulmonary disease; ESS, Epworth sleepiness scale. 
severity of OSA. Wereas male patients with OSA had larger neck circumferences in comparison to female patients with all severity categories, with increasing neck circumference associated with more severe OSA. In terms of the association of OSA with chronic health conditions such as chronic kidney disease, hypertension, diabetes, etc., no significant difference was noted in either gender.

In terms of factors that influence the severity of OSA, ordered logistic regression for females showed that for one centimeter increase in neck circumference, the odds of severe OSA versus the combined odds of mild and moderate OSA is 1.16-times greater $(P=0.012)$ (Table 4$)$. Ordered logistic regression for males showed that for one unit increase in ESS score, the odds of severe OSA versus the combined odds of mild and moderate OSA is 1.10 -times greater $(P=0.027)$. For both genders higher BMI, larger neck circumference, higher ESS, and the presence of hypertension increases the odds of having severe OSA versus the combined odds of mild and moderate OSA. The association of atrial fibrillation with severe OSA ( $\mathrm{OR}=3.70)$ was noted to be higher among females compared to men and hypertension was higher among males $(\mathrm{OR}=2.62)$ with severe $\mathrm{OSA}$, but was not statistically significant.

\section{Polysomnographic Characteristic According to Apnea Hypopnea Index Severity in Both Genders}

Figure 1 illustrates the polysomnographic results in both male and female OSA patients as per AHI severity. NREM stage 3 sleep is reduced in males with moderate-to-severe
OSA in comparison to females. Increased severity of OSA is associated with reducing NREM stage 3 sleep percentage in males. NREM stage 1 sleep percentage was increased in men with severe OSA as compared to women, while no significant difference was noted in REM sleep percentage. Among patients with severe OSA, respiratory $(P=0.014)$ and total arousal index $(P=0.014)$ were higher in men. The REM sleep related AHI was higher among women with all severity of OSA (Figure 1 and Table 5). Moreover, REM related AHI was higher among females compared to males, even with normal overall AHI (Table 6).

\section{Discussion}

This is one of the first studies to the best of our knowledge to demonstrate the ethnic and gender difference among Australian Aboriginal patients diagnosed to have OSA. This study showed that severe OSA was more common in males compared to females. Males had a higher AHI and higher arousal index. In comparison to men, Aboriginal women had milder severity of OSA and had more respiratory events during REM sleep (predominant REM OSA).

There is published evidence in the literature regarding gender differences in OSA manifestations in other ethnic groups. ${ }^{11,12,16,29}$ However, there is sparse knowledge specific to Indigenous populations, more so among the Australian Aboriginal population. In this study both genders, presence of higher body weight, BMI, and larger neck circumference were associated with severe OSA. However, among patients with severe OSA, the female

Table 4 Odds Ratio (OR) for Clinical Characteristics for Severe Obstructive Sleep Apnea Among Both Male and Female Study Participants

\begin{tabular}{|c|c|c|c|c|}
\hline \multirow[t]{2}{*}{ Risk Factors } & \multicolumn{2}{|l|}{ Females } & \multicolumn{2}{|l|}{ Males } \\
\hline & OR (95\% Cl) & P-value & OR $(95 \% \mathrm{Cl})$ & P-value \\
\hline Age & $0.99(0.95-1.02)$ & 0.447 & $1.03(0.99-1.06)$ & 0.118 \\
\hline BMI & 1.01 (0.96-I.07) & 0.617 & $1.04(0.96-1.13)$ & 0.300 \\
\hline Neck Circumference & $1.16(1.03-1.30)$ & $* 0.012$ & I.II (0.98-1.24) & 0.090 \\
\hline ESS & 1.01 (0.94-I.09) & 0.779 & $1.10(1.01-1.21)$ & $* 0.027$ \\
\hline Hypertension & $1.54(0.63-3.72)$ & 0.342 & $2.62(1.00-6.86)$ & 0.050 \\
\hline Diabetes & $0.53(0.22-1.29)$ & 0.162 & $0.42(0.16-1.13)$ & 0.087 \\
\hline Heart disease & $0.99(0.42-2.37)$ & 0.991 & $0.89(0.35-2.23)$ & 0.810 \\
\hline $\mathrm{AF}$ & $3.70(0.70-19.44)$ & 0.123 & $0.61(0.15-2.48)$ & 0.049 \\
\hline CKD & $0.88(0.3 \mathrm{I}-2.52)$ & 0.816 & I.63 (0.55-4.83) & 0.038 \\
\hline COPD/Asthma & $0.60(0.26-1.37)$ & 0.228 & $0.40(0.15-1.09)$ & 0.073 \\
\hline
\end{tabular}

Note: *Statistically significant.

Abbreviations: CKD, chronic kidney disease; BMI, body mass index; ESS, Epworth sleepiness scale; AF, atrial fibrillation; COPD, chronic obstructive pulmonary disease. 
Mild OSA

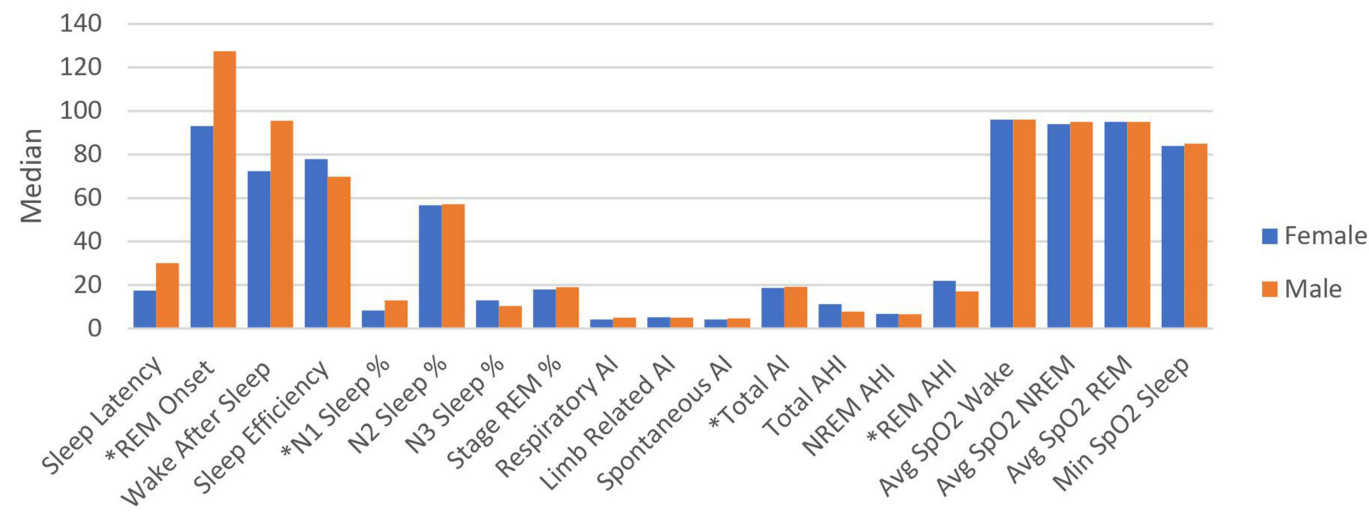

Moderate OSA

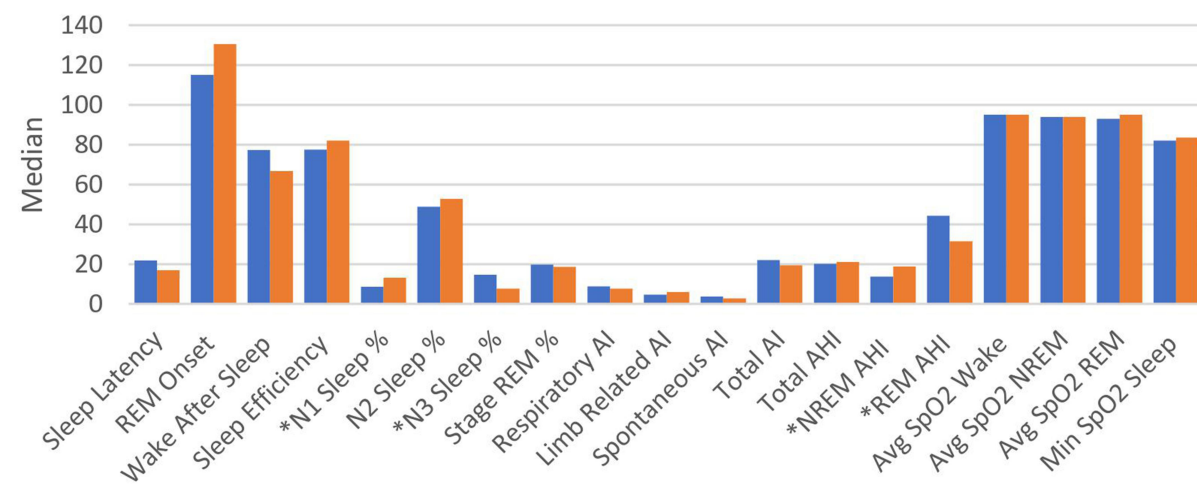

- Female

Male

Severe OSA

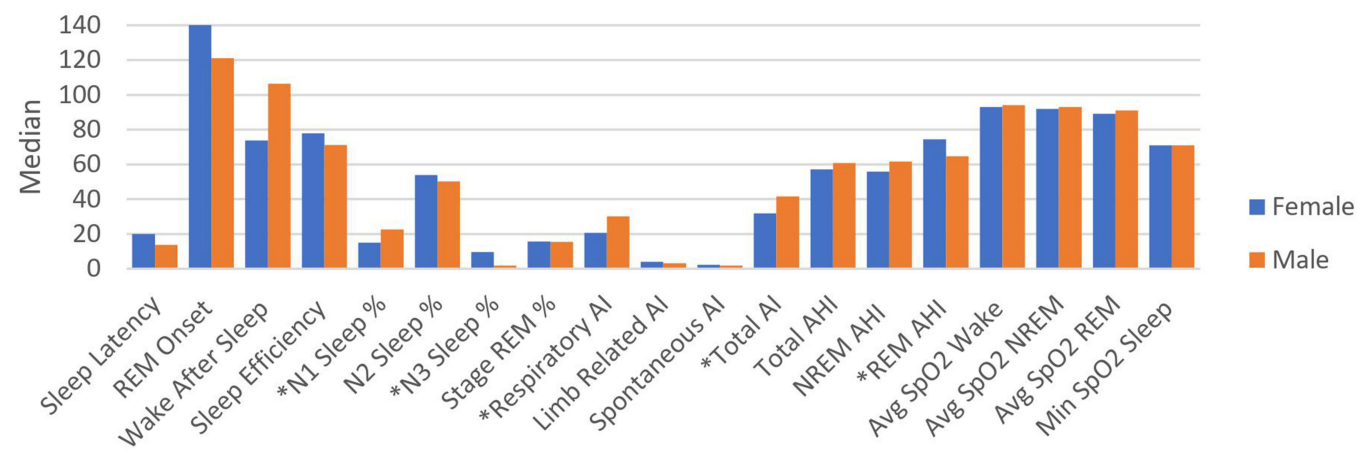

Figure I Polysomnographic characteristics among males and females with various severity of sleep apnea.

cohort were younger and had a higher BMI in contrast to males. This result may suggest that females who may gain excessive weight even at a younger age may have risk of developing severe OSA. Larger neck circumference is noted to predict the presence of OSA..$^{30-32}$ In our study male participants were noted to have a larger neck circumference compared to females with severe OSA, hence, neck circumference may represent as a screening tool in male Indigenous populations. Obesity is considered to be one of the main risk factors for OSA. ${ }^{33,34}$ It is an established notion that men classically have a more android (upper body) versus gynoid (lower body) fat distribution, leading to the hypothesis that men are more prone to OSA simply due to increased deposition of fat around the airway, reflecting as increased neck circumference. ${ }^{35}$

Analysis of the PSG architecture showed that male Aboriginal patients with OSA had increased stage NREM stage 1 sleep and reduced NREM stage 3 sleep 
Table 5 Prevalence of REM and NREM-Only OSA Among Male and Female Gender

\begin{tabular}{|l|l|l|l|l|}
\hline & Overall & Female & Male & $P$-value \\
\hline Total & 337 & 168 & 169 & \\
REM OSA & $292(86.6 \%)$ & $146(86.9 \%)$ & $146(86.4 \%)$ & 0.890 \\
*NREM OSA & $274(81.3 \%)$ & $125(74.4 \%)$ & $149(88.2 \%)$ & 0.001 \\
\hline
\end{tabular}

Note: *Statistically significant.

Abbreviations: REM, rapid eye movement; NREM, non rapid eye movement; OSA, obstructive sleep apnea.

Table 6 Prevalence of REM and NREM-Only OSA Among Male and Female Gender with Normal Total AHI

\begin{tabular}{|l|l|l|l|l|}
\hline & Overall & Female & Male & p-value \\
\hline $\begin{array}{l}\text { *Normal total AHI } \\
\text { but REM OSA } \\
\begin{array}{l}\text { Normal total AHI } \\
\text { but NREM OSA }\end{array}\end{array}$ & $2(0.7 \%)$ & $12(7.1 \%)$ & $4(2.4 \%)$ & 0.036 \\
\hline
\end{tabular}

Note: *Statistically significant.

Abbreviations: AHI, apnea hypopnea index; REM, rapid eye movement; NREM, non rapid eye movement; OSA, obstructive sleep apnea.

in contrast to females. This may represent that males with sleep apnea may have greater impact on sleep architecture and depth of sleep as compared to females. A previous study has shown that REM sleep related OSA is more common in women compared to men. ${ }^{12}$ Similarly we noticed in our study REM sleep related OSA was observed more commonly with all severity of OSA among females compared to males. Moreover, studies have demonstrated an association of REM sleep related OSA and hypertension. ${ }^{36,37}$ In our study we noticed the presence of hypertension increased the odds of having OSA. Hence, the presence of hypertension and REM sleep related OSA may warrant addressing therapeutic interventions, especially among female gender.

Few studies have documented sleep health issues among other Indigenous English speaking Organization for Economic Co-operation and Development (OECD) countries, such as New Zealand Māori's, Canadian First Nations, and United States Indigenous people. ${ }^{26,38,39}$ Obesity, symptomatic OSA, and the presence of other medical co-morbidities were noted in higher proportions, as noted in our study cohort. Chronic health conditions are noted to be highly prevalent in Indigenous populations, including Australian Aboriginal people. ${ }^{40-46}$ Under diagnosis or untreated OSA in this population may give rise to adverse health outcome. ${ }^{47}$ Ethnic and gender differences need to be considered in the clinical assessment of patients with OSA, which may itself represent a different phenotype. ${ }^{48,49}$ Our study highlights some important gender differences in sleep apnea and explore avenues to look for physiological basis for these observations and targeted interventions in the era of personalised sleep medicine. Further studies may be warranted in order to address prevention and management strategies in this population.

\section{Limitations of the Study}

The study results is limited to TEHS specific NT Aboriginal populations and the results cannot be generalised to wider other Australian Aboriginal populations or Indigenous groups. Furthermore, the high number of patients diagnosed with OSA in this study may be related to patients undergoing sleep study with already a high pretest probability of OSA.

\section{Conclusion}

OSA is highly prevalent among both Australian Aboriginal male and female genders. The presence of severe OSA was more common in males compared to females. Amongst patients with severe OSA, the female cohort were younger and had higher BMI in contrast to males who had larger neck circumference. PSG parameters showed that males had reduced stage N3 NREM sleep. Among females, OSA was noted predominantly during REM sleep. Higher BMI, larger neck circumference, higher ESS score, and the presence of hypertension increased the odds of having severe OSA for both genders in this study population. The study highlights some important differences in the way sleep apnea manifests in both genders and explores avenues to look for physiological bases for these observations and targeted interventions.

\section{Abbreviations}

AF, atrial fibrillation; AHI, apnea hypopnea index; AI, arousal index; TSI, Torres Strait Islander; ATSI, Aboriginal and/or Torres Strait Islander; ASA, Australasian Sleep Association; Avg $\mathrm{SpO}_{2}$, average oxygen saturation; BMI, body mass index; COPD, chronic obstructive pulmonary disease; CPAP, continuous positive airway pressure; CKD, chronic kidney disease; Circ, circumference; ESS, Epworth sleepiness score; HREC, Human Research Ethics Committees; $/ \mathrm{h}$, per hour; NREM, non rapid eye movement; N1, N2, N3, non-rapid eye movement sleep stage; NT, Northern Territory; NATA, National Association of Testing Authorities, Australia; OSA, obstructive sleep apnea; OR, odds ratio; PSG, 
polysomnography; REM, rapid eye movement; $\mathrm{SpO}_{2}$, oxygen saturation; TEHS, Top End Health Service; Mins, minutes.

\section{Acknowledgments}

We thank the sleep technologist at Darwin Respiratory and Sleep Health for the invaluable contribution towards this study. Institutions where work was performed: Department of Respiratory and Sleep Medicine, Royal Darwin Hospital, Darwin, Northern Territory, Australia and Darwin Respiratory and Sleep Health, Darwin, Northern Territory, Australia, 0810.

\section{Disclosure}

Robert Adams reports grants from ResMed Foundation, outside the submitted work. The authors report no other potential conflicts of interest for this work.

\section{References}

1. Senaratna CV, Perret JL, Lodge CJ, et al. Prevalence of obstructive sleep apnea in the general population: A systematic review. Sleep Med Rev. 2017;34:70-81. doi:10.1016/j.smrv.2016.07.002

2. Bonsignore MR, Suarez Giron MC, Marrone O, Castrogiovanni A, Montserrat JM. Personalised medicine in sleep respiratory disorders: focus on obstructive sleep apnoea diagnosis and treatment. Eur Respir Rev. 2017;26(146):170069. doi:10.1183/16000617.0069-2017

3. Benjafield AV, Ayas NT, Eastwood PR, et al. Estimation of the global prevalence and burden of obstructive sleep apnoea: a literature-based analysis. Lancet Respir Med. 2019;7(8):687-698. doi:10.1016/ S2213-2600(19)30198-5

4. Malhotra A, Orr JE, Owens RL. On the cutting edge of obstructive sleep apnoea: where next? Lancet Respir Med. 2015;3(5):397-403. doi:10.1016/S2213-2600(15)00051-X

5. Subramani Y, Singh M, Wong J, Kushida CA, Malhotra A, Chung F. Understanding Phenotypes of Obstructive Sleep Apnea: applications in Anesthesia, Surgery, and Perioperative Medicine. Anesth Analg. 2017;124(1):179-191. doi:10.1213/ANE.0000000000001546

6. Zinchuk A, Yaggi HY. Phenotypic Subtypes of OSA. A Challenge and Opportunity for Precision Medicine. Chest. 2020;157 (2):403-420. doi:10.1016/j.chest.2019.09.002

7. Zinchuk AV, Gentry MJ, Concato J, Yaggi HK. Phenotypes in obstructive sleep apnea: A definition, examples and evolution of approaches. Sleep Med Rev. 2017;35:113-123. doi:10.1016/j. smrv.2016.10.002

8. Villaneuva AT1, Buchanan PR, Yee BJ, Grunstein RR. Ethnicity and obstructive sleep apnoea. Sleep Med Rev. 2005;9(6):419-436. doi:10.1016/j.smrv.2005.04.005

9. Hnin K, Mukherjee S, Antic NA, et al. The impact of ethnicity on the prevalence and severity of obstructive sleep apnea. Sleep Med Rev. 2018;41:78-86. doi:10.1016/j.smrv.2018.01.003

10. Lin CM, Davidson TM, Ancoli-Israel S. Gender Differences in Obstructive Sleep Apnea and Treatment Implication. Sleep Med Rev. 2008;12(6):481-496.

11. Young T, Palta M, Dempsey J, Skatrud J, Weber S, Badr S. The occurrence of sleep disordered-breathing among middle aged adults. $N$ Engl J Med. 1993;328(17):1230-1235. doi:10.1056/NEJM19930 4293281704
12. Connor OC, Thornley SK, Hanley P. Gender differences in the polysomnography features of Obstructive Sleep Apnoea. Am J Respir Crit Care Med. 2000;161(5):1465-1472. doi:10.1164/ajrccm.161.5.99 04121

13. Wimms A, Woehrle H, Ketheeswaran S, Ramanan D, Armitstead J. Obstructive Sleep Apnea in Women: specific Issues and Interventions. Biomed Res Int. 2016;2016:1-9. doi:10.1155/2016/ 1764837

14. Lastra AC, Attarian HP. The Persistent Gender Bias in the Diagnosis of Obstructive Sleep Apnea: A Commentary. Gender Genome. 2018;2(2):43-48. doi:10.1177/2470289718787107

15. Christine ML, Terence MD, Sonia A. Gender Differences in Obstructive Sleep Apnea and Treatment Implications. Sleep Med Rev. 2008;12:481-496. doi:10.1016/j.smrv.2007.11.003

16. Quintana-Gallego E, Carmon-Bernal C, Capote F, et al. Gender differences in obstructive sleep apnea syndrome: a clinical study of 1166 patients. Respir Med. 2004;98(10):984-989. doi:10.1016/j. rmed.2004.03.002

17. Young T. Analytic epidemiology studies of sleep-disordered breathing: what explains the gender difference in sleep disordered breathing? Sleep. 1993;16(suppl_8):S1-2. doi:10.1093/sleep/16. suppl_8.S1

18. Chen X, Wang R, Zee P, et al. Racial/ethnic differences in sleep disturbances: the Multi-Ethnic Study of Atherosclerosis (MESA). SLEEP. 2015;38(6):877-888. doi:10.5665/sleep.4732

19. Dudley KA, Patel SR. Disparities and genetic risk factors in obstructive sleep apnea. Sleep Med. 2016;18:96-102. doi:10.1016/j.sleep. 2015.01.015

20. Genta PR, Marcondes BF, Danzi NJ, Lorenzi-Filh G. Ethnicity as a risk factor for obstructive sleep apnea: comparison of Japanese descendants and white males in São Paulo, Brazil. Braz J Med Biol Res. 2008;41(8):728-733. doi:10.1590/S0100-879X20080008 00015

21. Indigenous Peoples Overview - World Bank Group.2010 Available from: https://www.worldbank.org/en/topic/indigenouspeoplesStateof theWorld's.

22. Indigenous Peoples.2010 Department of Economic and Social Affairs Division for Social Policy and Development Secretariat of the Permanent Forum on Indigenous Issues ST/ESA/328 United Nations publication Sales No. 09.VI.13 ISBN 92-1-130283-7.

23. Estimates of Aboriginal and Torres Strait Islander Australians. Australian Bureau of Statistics. Canberra 2016. https://www.abs. gov.au.

24. Woods CE, McPherson K, Tikoft E, et al. Sleep disorders in Aboriginal and Torres Strait Islander people and residents of regional and remote Australia. J Clin Sleep Med. 2015;11(11):1263-1271. doi:10.5664/jcsm.5182

25. Woods CE, Usher K, Maguire GP. Obstructive sleep apnoea in adult indigenous populations in high-income countries: an integrative review. Sleep Breath. 2015;19(1):45-53.

26. Kara M, Mihaere, Ricci Harris, Philippa H, Gander, Papaarangi M. Reid, Gordon Purdie, Bridget Robson, Alister Neill Obstructive Sleep Apnea in New Zealand Adults: prevalence and Risk Factors Among Māori and Non-Māori. Sleep. 2009;32(7):949-956. doi:10.1093/ sleep/32.7.949

27. Guglielmia O, Lanterib P, Garbarinoa S. Association between socioeconomic status, belonging to an ethnic minority and obstructive sleep apnea: a systematic review of the literature. Sleep Med. 2019;57:100-106. doi:10.1016/j.sleep.2019.01.042

28. Heraganahally SS, Kruavit A, Oguoma VM, et al. Sleep apnoea among Australian Aboriginal and Non- Aboriginal patients in the Northern Territory of Australia- a comparative study. Sleep J. 2019;43(3):pii: zsz248. doi:10.1093/sleep/zsz248

29. Cairns A, Poulos G, Bogan R. Sex differences in sleep apnea predictors and outcomes from home sleep apnea testing. Nat Sci Sleep. 2016;8:197-205. doi:10.2147/NSS.S101186 
30. Ahbab S, Ataoğlu E, Tuna M, et al. Neck circumference, metabolic syndrome and obstructive sleep apnea syndrome; Evaluation of possible linkage. Med Sci Monit. 2013;19:111-117. doi:10.12659/MSM. 883776

31. Davies RJ, Ali NJ, Stradling JR. Neck circumference and other clinical features in the diagnosis of the obstructive sleep apnoea syndrome. Thorax. 1992;47(2):101-105. doi:10.1136/thx.47.2.101

32. Kim SE, Park BS, Park SH, et al. Predictors for Presence and Severity of Obstructive Sleep Apnea in Snoring Patients: significance of Neck Circumference. J Sleep Med. 2015;12(2):34-38. doi:10. 13078/jsm. 15007

33. Romero-Corral A, Caples SM, Lopez-Jimenez F, Somers VK. Interactions between obesity and obstructive sleep apnea: implications for treatment. Chest. 2010;137(3):711-719. doi:10.1378/chest. 09-0360

34. Garvey JF, Pengo MF, Drakatos P, Kent BD. Epidemiological aspects of obstructive sleep apnea. J Thorac Dis. 2015;7(5):920-929. doi:10.3978/j.issn.2072-1439.2015.04.52

35. Millman RP, Carlisle CC, McGarvey ST, Eveloff SE, Levinson PD. Body fat distribution and sleep apnea severity in women. Chest. 1995;107(2):362-366. doi:10.1378/chest.107.2.362

36. Appleton SL, Vakulin A, Martin SA, et al. Hypertension Is Associated With Undiagnosed OSA During Rapid Eye Movement Sleep. Chest. 2016;150(3):495-505. doi:10.1016/j.chest.2016.03.010

37. Mansukhani MP, Kolla BP, Somers VK. Hypertension and Cognitive Decline: implications of Obstructive Sleep Apnea. Fron Cardiovasc Med. 2019;6:96. doi:10.3389/fcvm.2019.00096

38. Spuy IVD, Karunanayake CP, Dosman JA, et al. Determinants of excessive daytime sleepiness in two First Nation communities. BMC Pulm Med. 2017;17(1):192. doi:10.1186/s12890-017-0536-x

39. Froese CL, Butt A, Mulgrew A, et al. Depression and sleep-related symptoms in an adult, indigenous, north american population. J Clin Sleep Med. 2008;4(4):356-361. doi:10.5664/jcsm.27237

40. Bramley D, Hebert P, Jackson R, Chassin M. Indigenous disparities in disease-specific mortality, a cross-country comparison: new Zealand, Australia, Canada, and the United States. $N Z$ Med J. 2004;117(1207):U1215.
41. Randall DA, Lujic S, Havard A, Eades SJ, Jorm L. Multimorbidity among Aboriginal people in New South Wales contributes significantly to their higher mortality. Med J Aust. 2018;209(1):19-23. doi:10.5694/mja17.00878

42. Kruavit A, Fox M, Pearson R, Heraganahally S. Chronic respiratory disease in the regional and remote population of the Northern Territory Top End: A perspective from the specialist respiratory outreach service. Aust J Rural Health. 2017;25(5):275-284. doi:10.1111/ ajr. 12349

43. Schubert J, Kruavit A, Mehra S, Wasgewatta S, Chang AB, Heraganahally S. Prevalence and nature of lung function abnormalities among indigenous Australians referred to specialist respiratory outreach clinics in the Northern Territory. Intern Med J. 2019;49 (2):217-224. doi:10.1111/imj.14112

44. Heraganahally SS, Wasgewatta SL, McNamara K, et al. Chronic Obstructive Pulmonary Disease In Aboriginal Patients of The Northern Territory Of Australia: A Landscape Perspective. Int J Chron Obstruct Pulmon Dis. 2019;14(5):2205-2217. doi:10.21 47/COPD.S213947

45. Heraganahally SS, Wasgewatta SL, McNamara K, et al. Chronic obstructive pulmonary disease with and without bronchiectasis in Aboriginal Australians - a comparative study. Intern Med J. 2019. doi:10.1111/imj.14718

46. Williams NJ, Grandner MA, Snipes SA, et al. Racial/ethnic disparities in sleep health and health care: importance of the sociocultural context. Sleep Health. 2015;1(1):28-35. doi:10.1016/j.sleh.2014. 12.004

47. Punjabi NM, Caffo BS, Goodwin JL, et al. Sleep-disordered breathing and mortality: a prospective cohort study. PLoS Med. 2009;6(8): e1000132. doi:10.1371/journal.pmed.1000132

48. Osman AM, Carter SG, Carberry JC, Eckert DJ. Obstructive sleep apnea: current perspectives. Nat Sci Sleep. 2018;10:21-34. doi:10.2147/NSS.S124657

49. Ayub S, Wo CHJ. Obstructive sleep apnea in women. J Sleep Med. 2019;16(2):75-80. doi:10.13078/jsm.190047

\section{Publish your work in this journal}

Nature and Science of Sleep is an international, peer-reviewed, open access journal covering all aspects of sleep science and sleep medicine, including the neurophysiology and functions of sleep, the genetics of sleep, sleep and society, biological rhythms, dreaming, sleep disorders and therapy, and strategies to optimize healthy sleep.
The manuscript management system is completely online and includes a very quick and fair peer-review system, which is all easy to use. Visit http://www.dovepress.com/testimonials.php to read real quotes from published authors. 